\title{
EBSD Observation of Micro Crack Morphologies after Thermal Exposure in Thermal Barrier Coatings*
}

\author{
Kazunari FUJIYAMA**, Hikaru NAKASEKO***, Yukihiro KATO*** \\ and Hirohisa KIMACHI** \\ **Department of Mechanical Engineering, Meijo University \\ 1-501 Shiogamaguchi, Tempaku-ku, Nagoya, Japan \\ E-mail:fujiyama@ccmfs.meijo-u.ac.jp \\ ${ }^{* * *}$ Graduate School of Mechanical Engineering, Meijo University \\ 1-501 Shiogamaguchi, Tempaku-ku, Nagoya, Japan
}

\begin{abstract}
Micro-cracking process in TBCs(Thermal Barrier Coatings) due to thermal exposure was investigated using SEM(Scanning Electron Microscope) and EBSD(Electron BackScatter Diffraction) observation. Splat particle morphologies in TBCs were clearly visualized by IPF (Inverse Pole Figure) mapping. The splat structure of top coat was consisted with large granular particle region and cluster of small columnar particle region. Cracks were observed along the interfaces of large granular particle region and the cluster of small columnar particle region, along the interfaces among large granular particles and across the cluster of small columnar particles transgranularly perpendicular to columnar crystal growth direction. The onset time of extensive macro crack formation was corresponding to the $\mathrm{Cr}$ oxide growth at TGO(Thermally Grown Oxide) to some extent. Thus EBSD observation can be used as a powerful tool for crystallographic observation of TBC, associated with SEM and optical microscope observation.
\end{abstract}

Key words: TBC, EBSD, Thermal Exposure, Crack, Pores, TGO

\section{Introduction}

Recently, as high temperature components are used beyond its ultimate performance, protective coatings become effective measures to assure the endurance of high efficiency apparatus. Thermal barrier coating(TBC) is one of the most effective way to protect the damage from thermal exposure of hot gas path components in gas turbines ${ }^{(1)}$. As TBCs are used in very severe conditions, thermally induced damage and material degradation are inevitably induced during service and delamination of coating layer could occur finally as the result of damage accumulation. However, there are so many factors affecting damage evolution that it is still not clear how the damage and degradation mechanisms determine the delamination life ${ }^{(2)}$. Furthermore, the precise microstructural feature of TBC top coat has not been clearly observed by the conventional optical microscope or scanning electron microscope (SEM) because those means could not give the comprehensive crystallographic information of ceramic coatings. Though electron backscatter diffraction (EBSD) method ${ }^{(3)}$ has been becoming more and more popular as the visual crystallographic observation tool, the application of EBSD to the observation has not been so popular according to the difficulty in preparing the observation surface of TBC. One of the objectives of this paper is to show the EBSD observation results of thermal exposure samples of TBC top coat and the effectiveness of this method for the study of damage process. The other is to evaluate the 
damage process toward delamination life of TBCs at two heat temperatures considering top coat sintering, change of pore distribution and evolution of TGOs as the major affecting factors.

\section{Experimental procedure}

\subsection{Material and specimen preparation}

Figure 1 shows TBC specimen geometry consisted with top coat, bond coat and substrate as follows.

Top coat : $8 \mathrm{wt} \% \mathrm{Y}_{2} \mathrm{O}_{3}-\mathrm{ZrO}_{2}(1 \mathrm{~mm}$ thick); APS(Atmospheric Plasma Spraying)

Bond coat : CoNiCrAlY(100 $\mu \mathrm{m}$ thick); LPPS(Low Pressure Plasma Spraying)

Substrate : MA263(2mm thick)

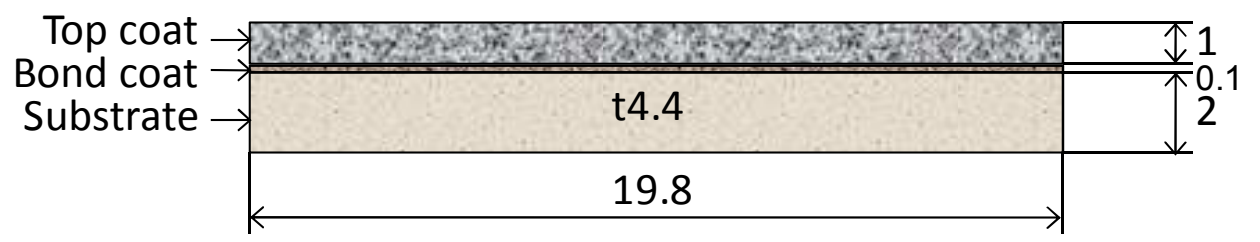

Fig.1 TBC specimen geometry.

Thermal exposure tests were conducted using an electric furnace. The conditions of thermal exposure tests are listed in Table 1. Specimens were picked up from the furnace after each prescribed heating time and cut at the middle of the specimen along thickness direction. The cut surface was finished with colloidal alumina with the particle diameter as 0.1 to $3 \mu \mathrm{m}$.

Table 1 Thermal exposure test conditions.

\begin{tabular}{|c|c|}
\hline Temperature $\left({ }^{\circ} \mathrm{C}\right)$ & Exposure time $(\mathrm{h})$ \\
\hline 900 & $100,200,300,500,1000$ \\
\hline 1000 & $50,75,100$ \\
\hline
\end{tabular}

\subsection{Optical microscope observation}

Optical microscope observation was conducted using digital optical microscope. Pores were observed and traced manually and then processed by image processing software. TGO thickness was estimated by the measured total area of TGO ((Thermally Grown Oxide ; including both $\mathrm{Al}$ oxide and $\mathrm{Cr}$ oxide) divided by the total length of the center contour line along the measured oxide.

\subsection{Scanning electron microscope (SEM) and electron backscatter diffraction (EBSD) observation}

SEM observation was conducted using the thermal field-emission scanning electron microscope mainly to obtain crack morphologies. Observed cracks were traced manually and then processed by image processing software. TGO layer was investigated using EDS (Energy Dispersive Spectroscopy) system of SEM to identify the elements of oxides.

EBSD observation was conducted using Tex SEM Laboratory OIM 4.6 system attached to the SEM. IPF(Inverse Pole Figure) maps were obtained from near bond coat region within top coat(bottom region), middle of top coat thickness(middle region) and near surface region of top coat(top region). The assumed crystal system for EBSD observation was $\mathrm{ZrO}_{2}$ cubic system which was proved to be the most acceptable system in this case by 
preliminary check tests.

\section{Results and discussion}

\subsection{Optical microscope observation}

Figure 2 shows the delamination process at $900^{\circ} \mathrm{C}$ exposure tests. Macro cracks grow laterally in the top coating just above the bond coating. At the surface macro crack is located at the interface between top coating and bond coating besides at the mid section crack is located above the bond coat within top coat.

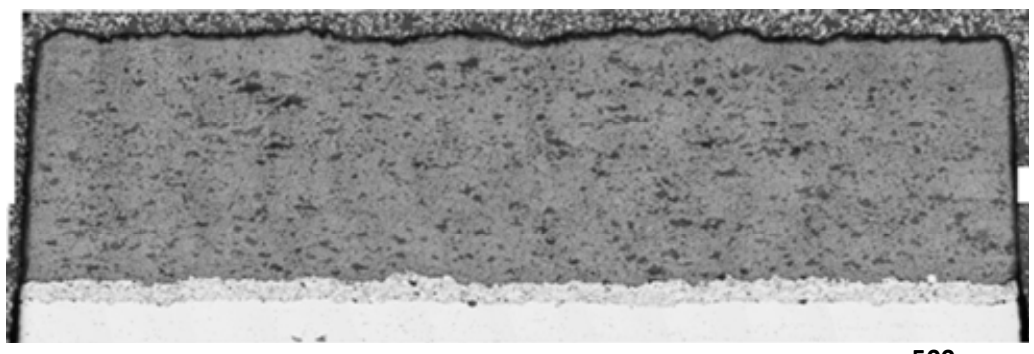

$500 \mu \mathrm{m}$

(a)As sprayed

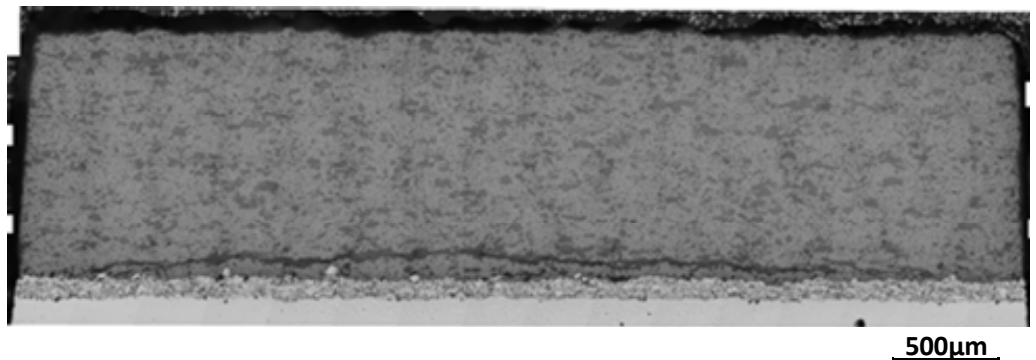

(b) $900^{\circ} \mathrm{C} 100 \mathrm{~h}$

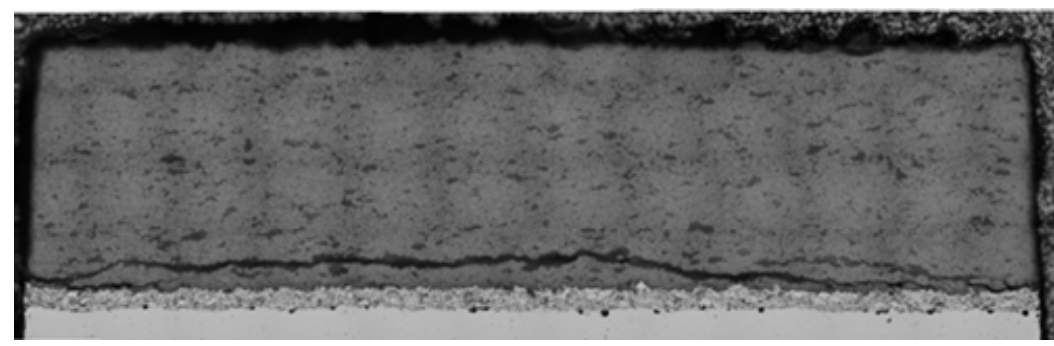

$500 \mu \mathrm{m}$

(c) $900^{\circ} \mathrm{C} 300 \mathrm{~h}$

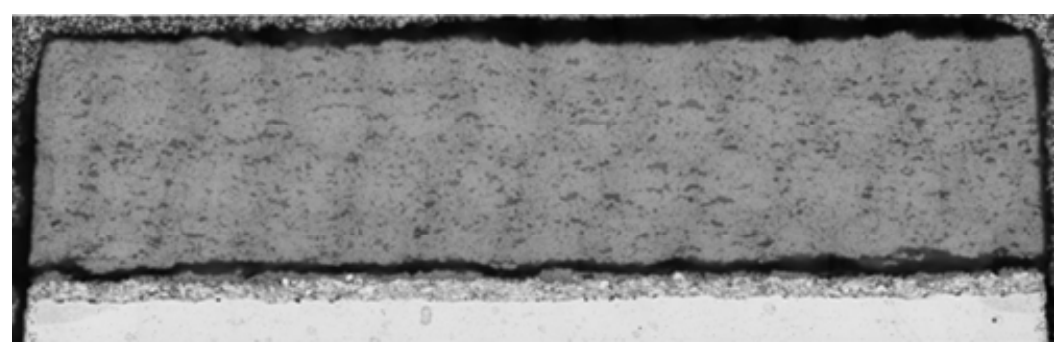

$500 \mu \mathrm{m}$

(d) $900^{\circ} \mathrm{C} 1000 \mathrm{~h}$

Fig.2 Delamination morphologies at $900{ }^{\circ} \mathrm{C}$ exposure tests. 
Figure 3 shows optical microscope observation of top coat at the region near the bond coat. Reduction of pore is observed for samples after thermal exposure compared with the sample as sprayed but the decreasing trend with exposure time is not monotonic. Fig.4 shows the traced pore image for image processing based on optical microscope photos. Area fraction of pores was obtained as the area ratio of pores (black area) and the observed area.

Figure 5 shows the trend of area fraction of pores against thermal exposure time. Reduction in area fraction of pores was observed at the initial stage of heating but the decreasing trend was not monotonic. The area fraction of pores showed similar levels after $500 \mathrm{~h}$ and $75 \mathrm{~h}$ for $900{ }^{\circ} \mathrm{C}$ and $1000^{\circ} \mathrm{C}$ exposure respectively.

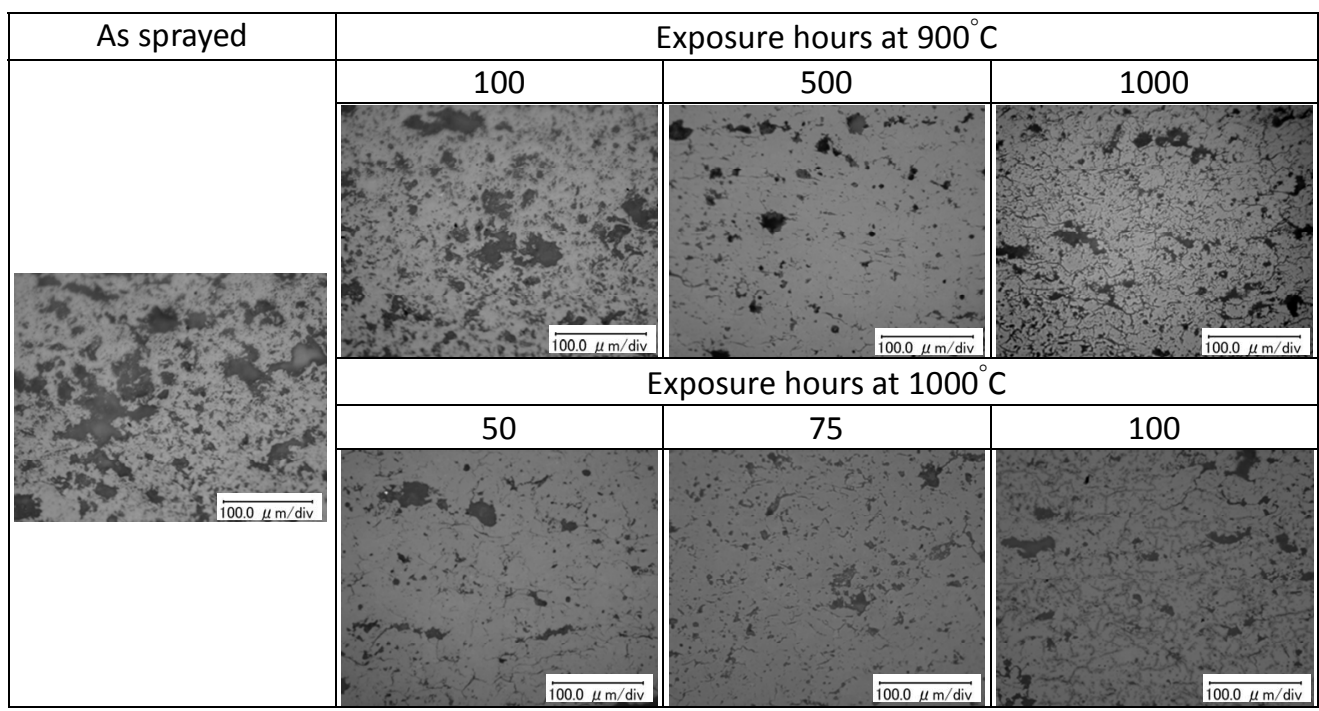

Fig.3 Optical microscope observation of top coat.

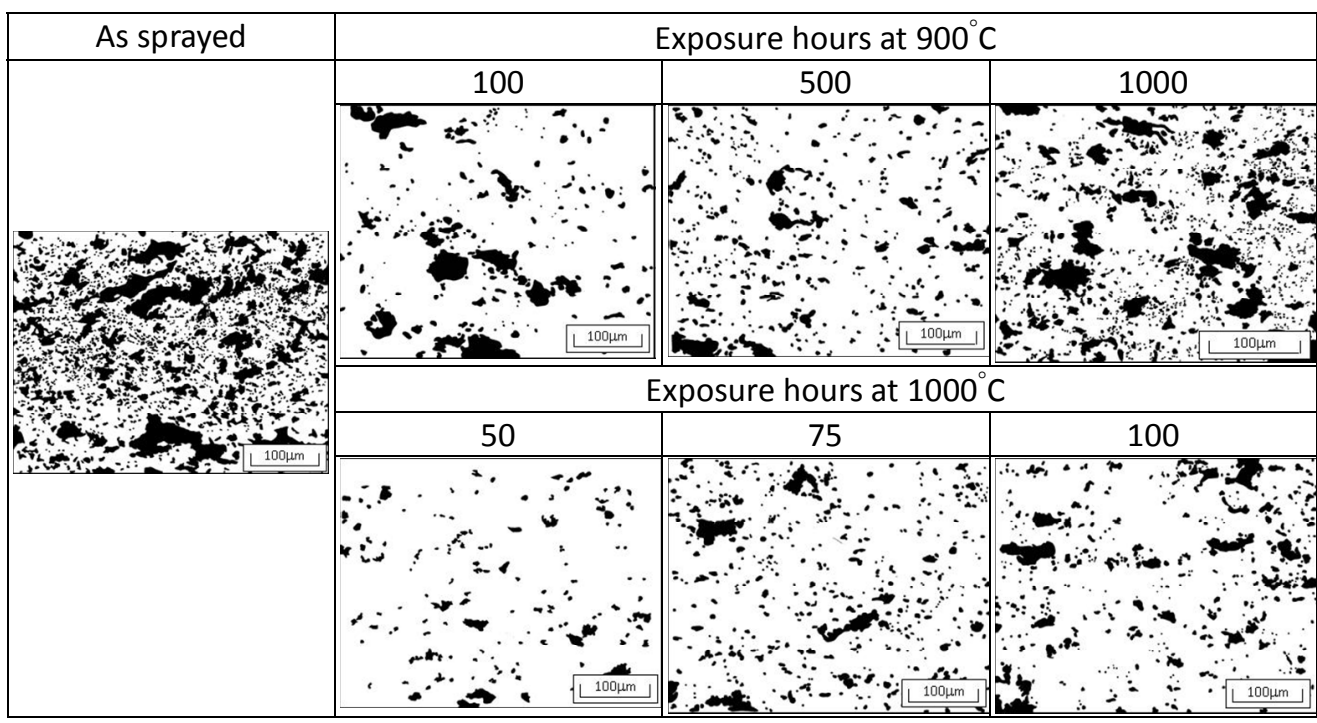

Fig.4 Pore area trace of optical microscope image in top coat. 


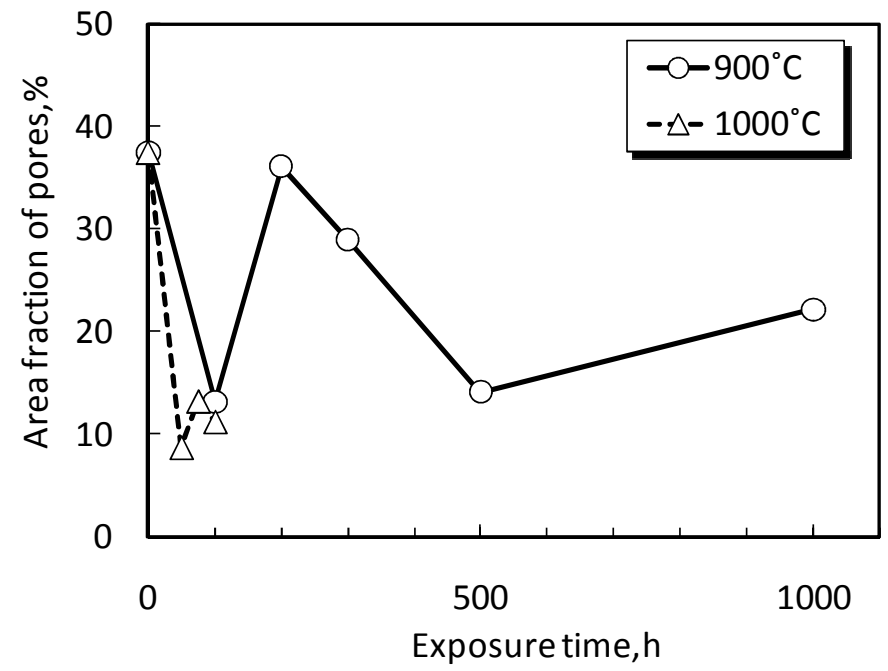

Fig.5 The trend of area fraction of pores in top coat against exposure time.

\subsection{SEM and EBSD observation}

Figure 6 shows the SEM image and EBSD IPF maps for $900{ }^{\circ} \mathrm{C} 500 \mathrm{~h}$ exposure sample indicating the matching of cracks and pores for each observation image. IPF maps clearly reveal the splat particle morphologies and the crystal orientation perpendicular to the observed plane in this study. To obtain clear map image, specimen surface polishing treatment is quite important and should be carefully finished. The splat morphologies are divided into two typical groups. One is the large granular type particles which might not be melted completely at the spraying process, and the other is the cluster of small columnar particles which might be formed by crystallization from completely melted particles. Cracks are found to be affected by splat microstructures after crystallization completed.

Figures 7 and 8 shows IPF maps from bottom to top region of top coat for samples as sprayed and after $900^{\circ} \mathrm{C} 500 \mathrm{~h}$ exposure. Though there is no significant difference of crystallographic features and crack morphologies in test samples and locations, some crack growth and reduction of pores could occur in the sample after thermal exposure.

Figure 9 shows IPF maps in higher magnification for categorizing crack morphologies. There are three typical cracking patterns. The first is the interface cracking between large granular particles and the cluster of small columnar particles, the second is the interface cracking along large granular particles which is often perpendicular to thickness direction of coating and the third is the transgranular cracking across the cluster of small columnar particles. The cracking orientation seems almost perpendicular to crystal growth direction at the columnar small particle regions. Those cracks are thought to be introduced during cooling process after crystallization was completed. For heated samples cracks are thought to grow from initially introduced cracks during spraying process and increasing in number at successive exposure test. There is no strong dependence of locations in cracking morphologies though it does not include the macro cracking region. 


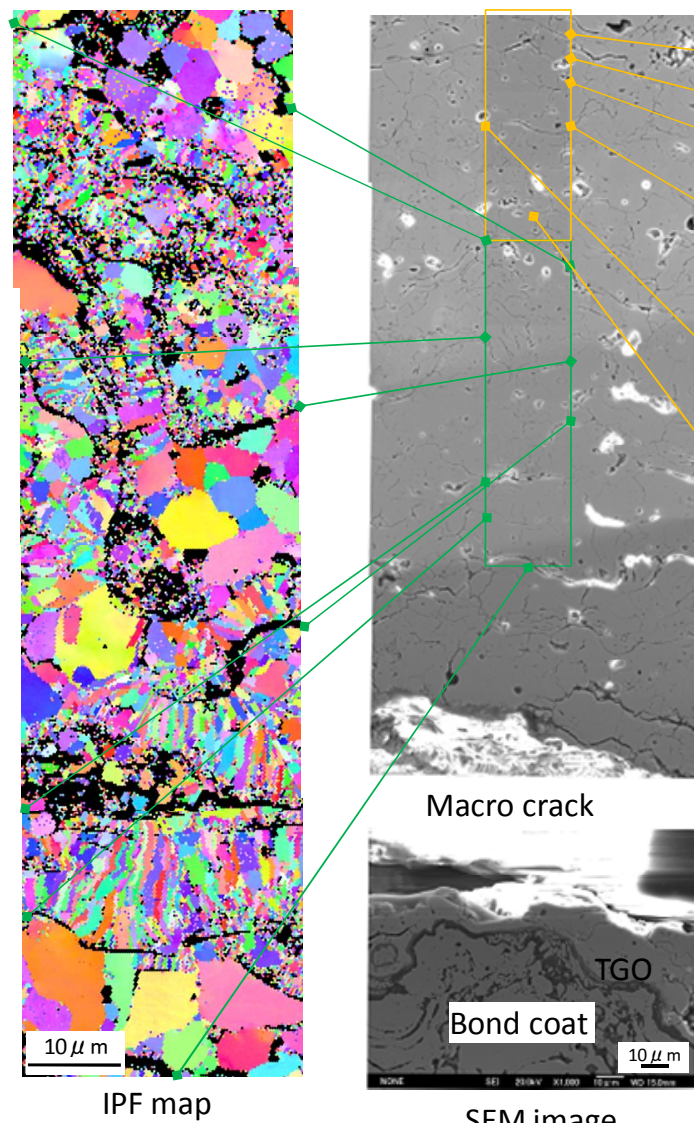

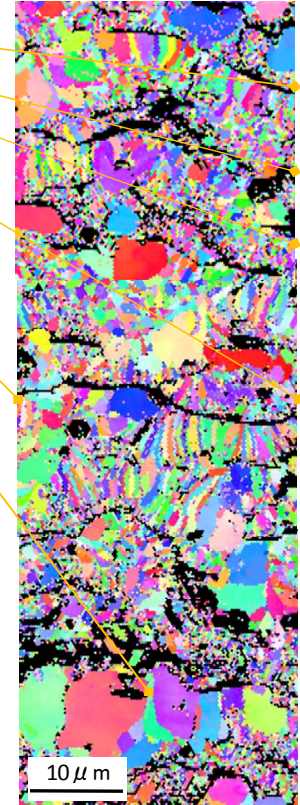

IPF map

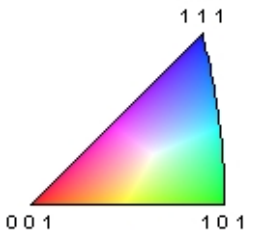

Fig.6 Matching of IPF maps and SEM image for the sample exposed at $900^{\circ} \mathrm{C}$ for $500 \mathrm{~h}$.

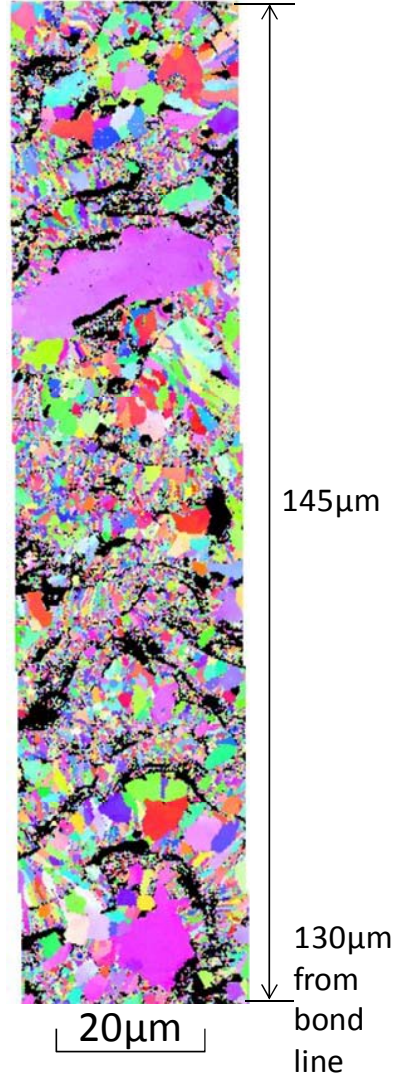

(a)Bottom region

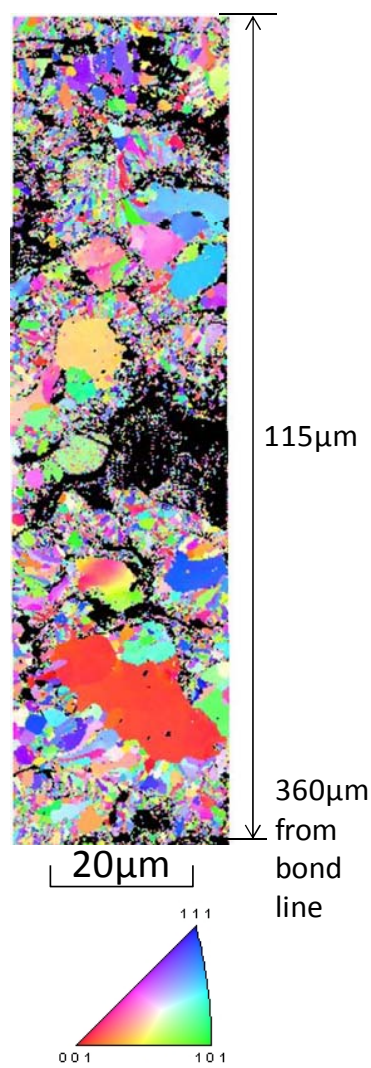

(b)Middle region

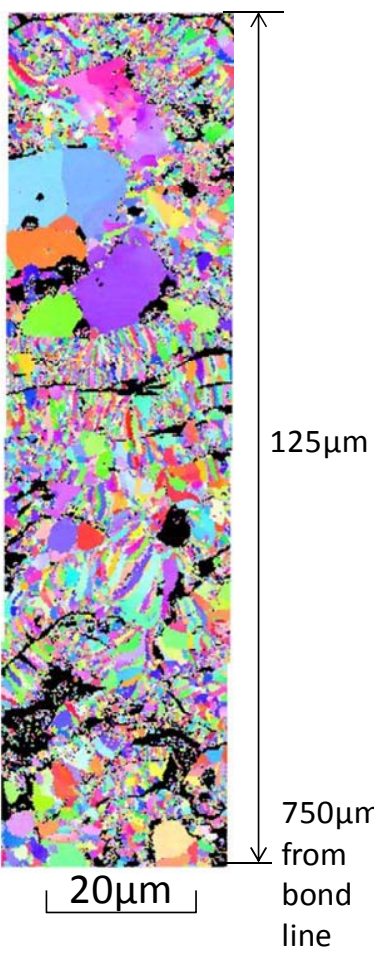

(c)Top region

Fig.7 IPF maps of as sprayed top coat. 


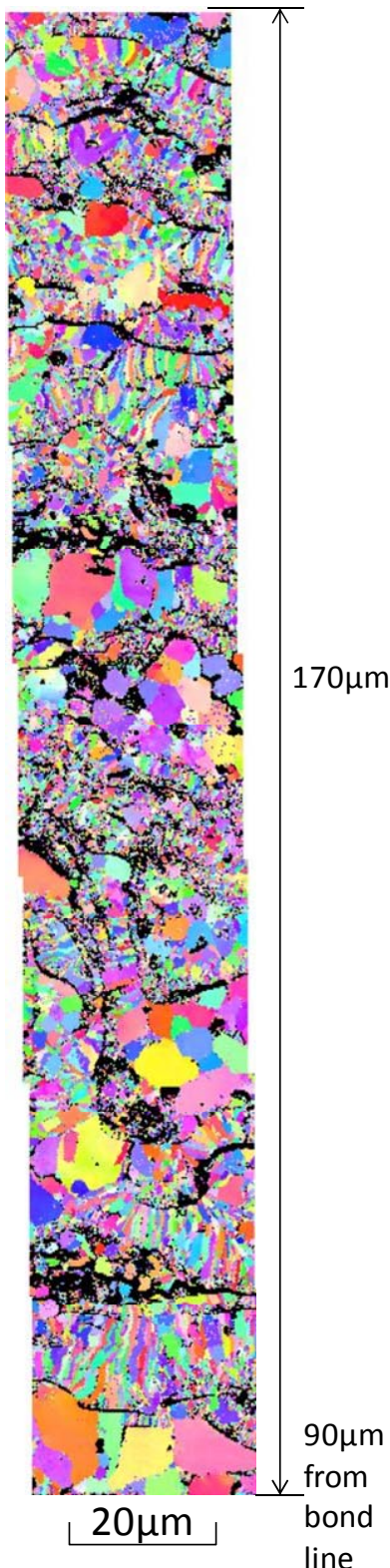

(a)Bottom region

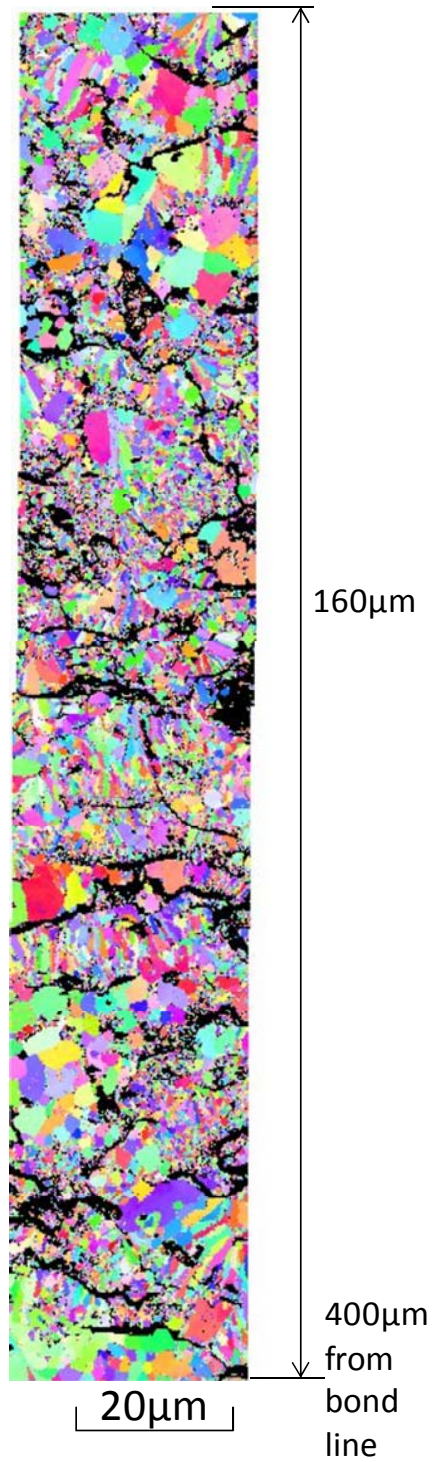

(b)Middle region
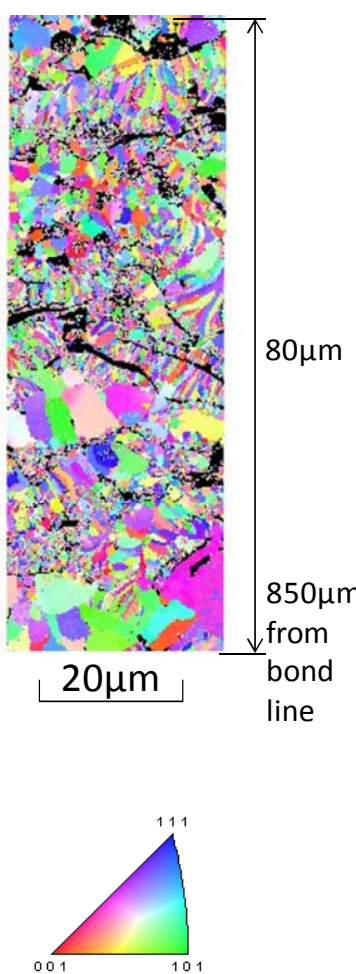

Fig.8 IPF maps for the sample exposed at $900^{\circ} \mathrm{C}$ for $500 \mathrm{~h}$. 


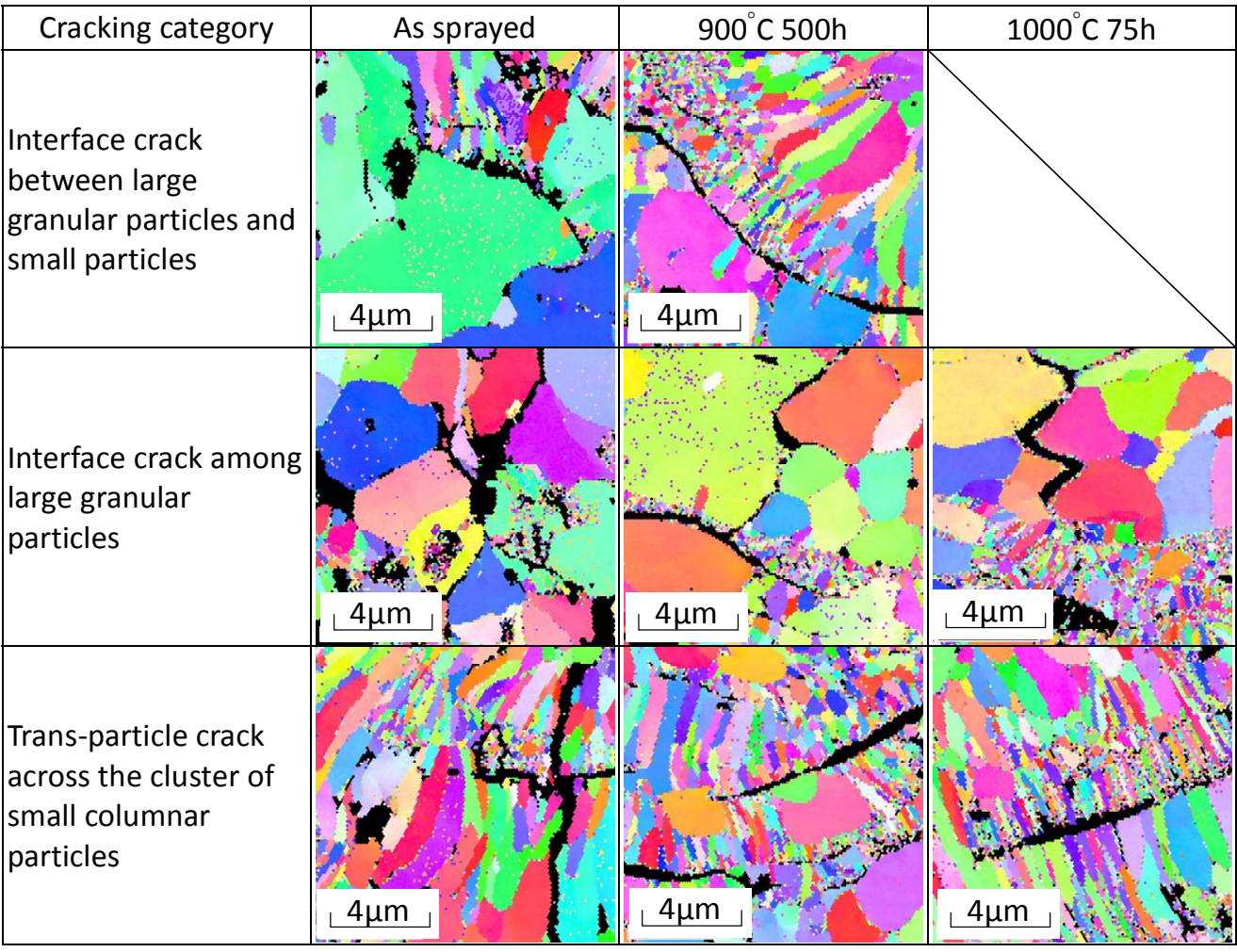

Fig.9 Crack morphologies observed by IPF maps at top coat.

Figure 10 shows the trace of micro cracks based on SEM observation in the top coat near bond coat region. The crack orientation is relatively random according to the splat morphologies as shown above. Crack growth may occur due to the coalescence of micro cracks which becomes more frequently at the later stage of exposure time. Crack length density is obtained as the ratio of total sum of crack length and the observed area.

Figure 11 shows the trend of crack length density against exposure time. Significant increase in crack length density was observed at the final stage of delamination for both exposure temperatures.

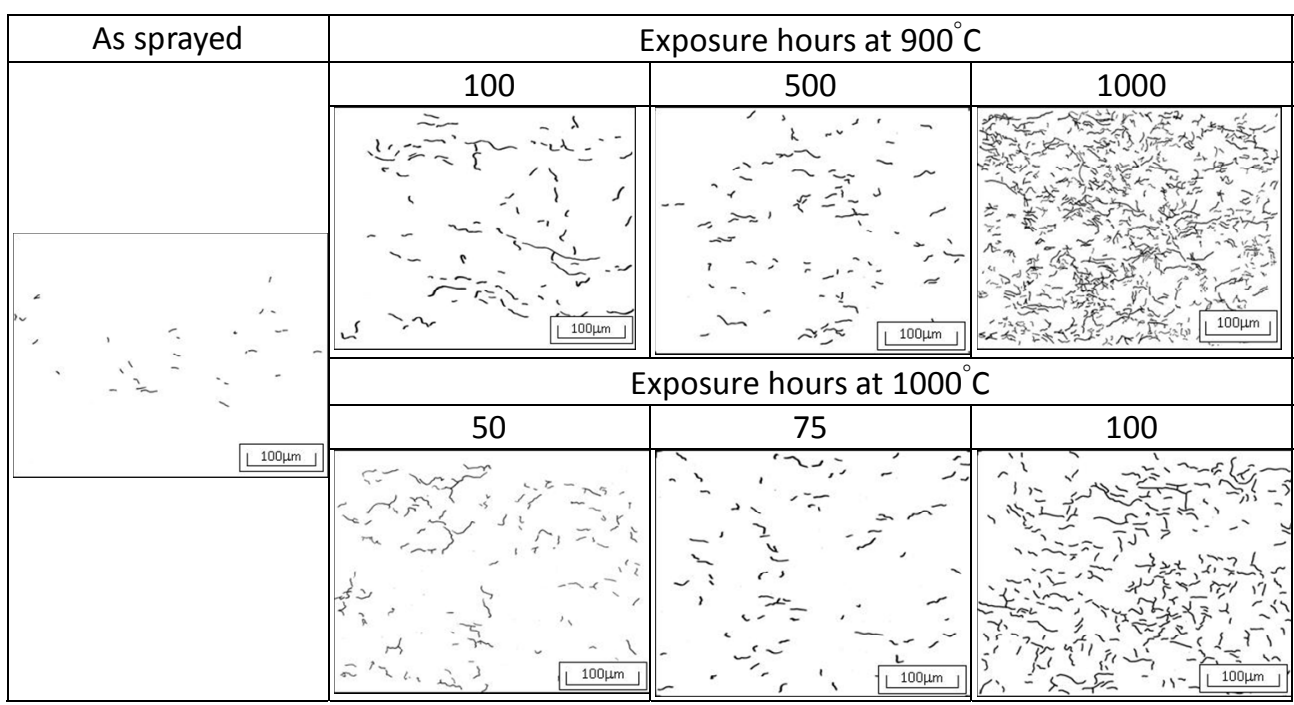

Fig.10 Trace of cracks in top coat. 


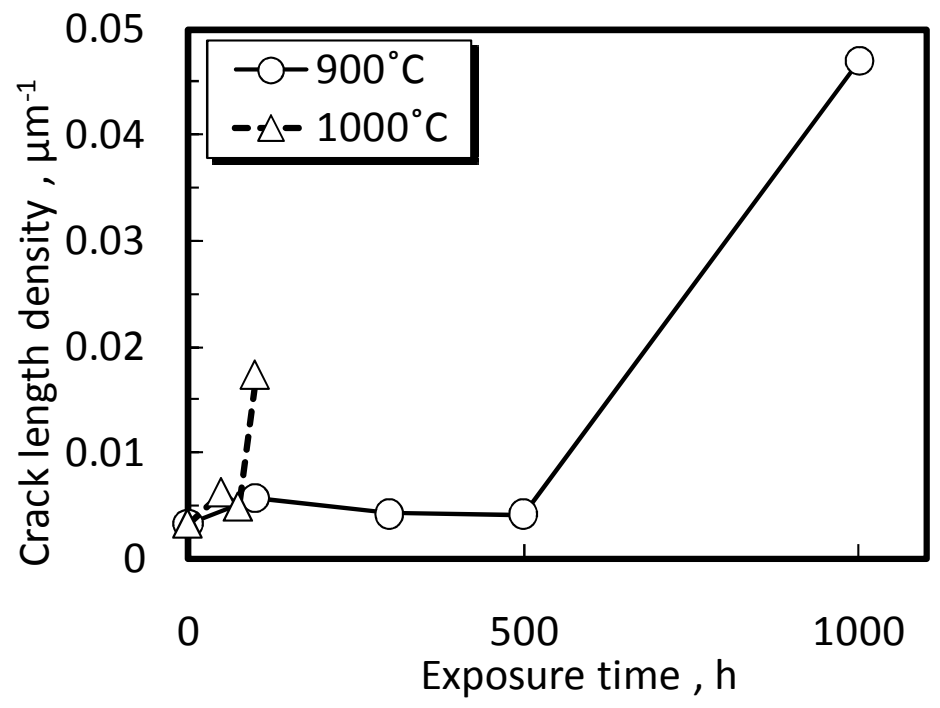

Fig.11 Crack length density in top coat against exposure time.

Figure 12 shows the EDS analysis results of top coat. Al oxides and $\mathrm{Cr}$ oxides were observed at TGO. Cr oxides are bulging toward top coat from TGO film consisted of Al oxides and enhancing top coat cracking.

Figure 13 shows the trend of average TGO thickness against exposure time. The initial significant increase and successive constant trend of TGO thickness was observed for both exposure temperatures. Fig.14 shows the area fraction (\%) of $\mathrm{Al}$ oxide and $\mathrm{Cr}$ oxide to total $(\mathrm{Al}+\mathrm{Cr})$ oxide area against exposure time. For $\mathrm{Al}$ oxide, the growth trend is almost similar in both exposure temperatures but for $\mathrm{Cr}$ oxide the growth trend is quite different. The time to exceed $30 \%$ area fraction might corresponding to the onset of intensive cracking in top coat. Thus, the $\mathrm{Cr}$ oxide growth was thought to be an enhancing factor of cracking in top coat.

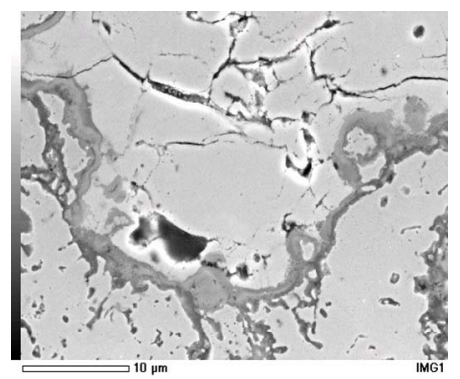

(a)SEM image

Al oxide

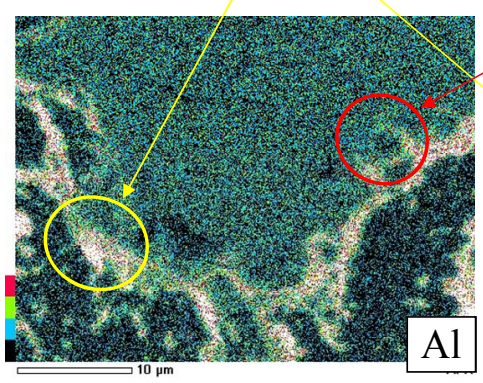

(c) Aluminum

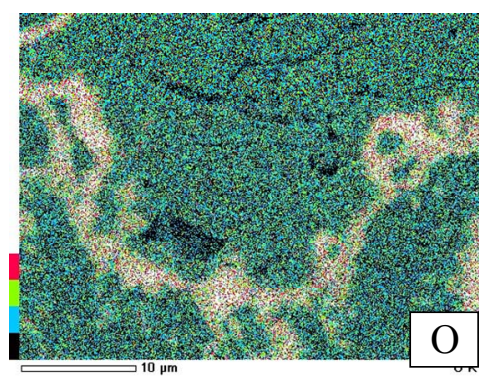

(b) Oxygen image
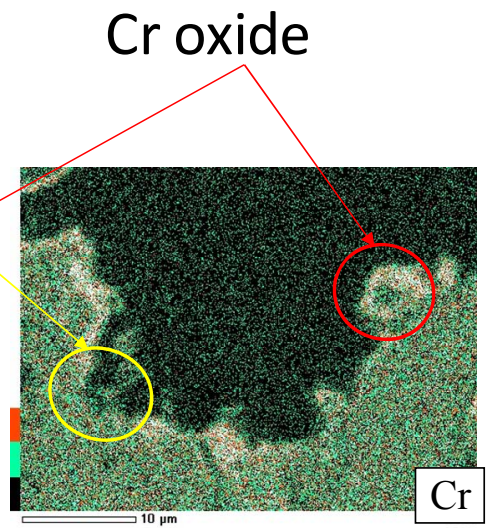

(d) Chromium

Fig.12 Observation and element analysis of TGO 


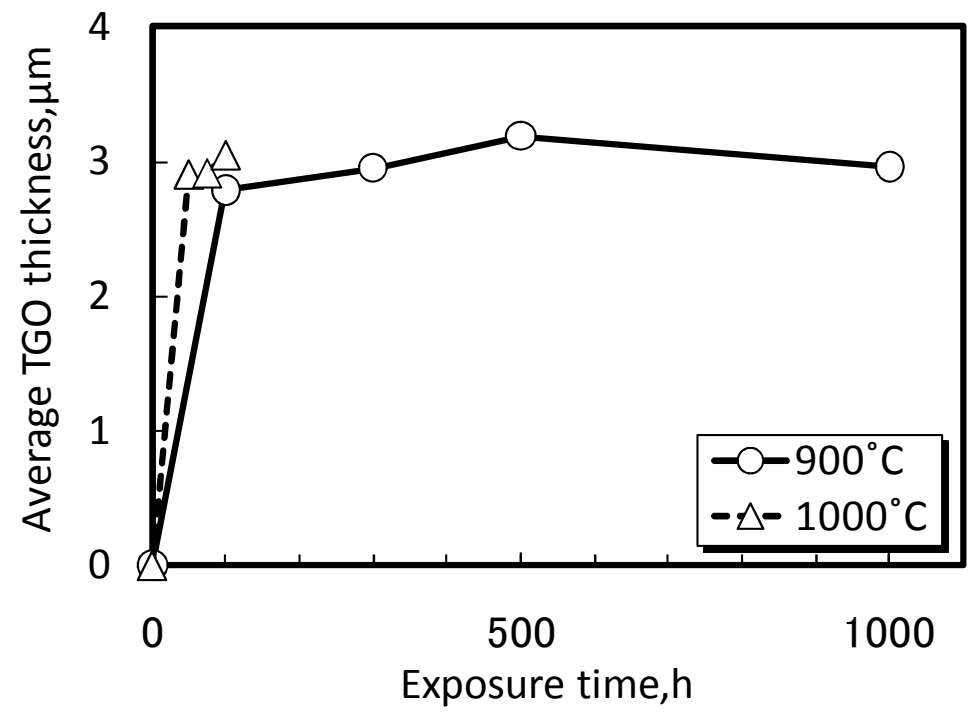

Fig.13 Trend of average TGO thickness against exposure time.

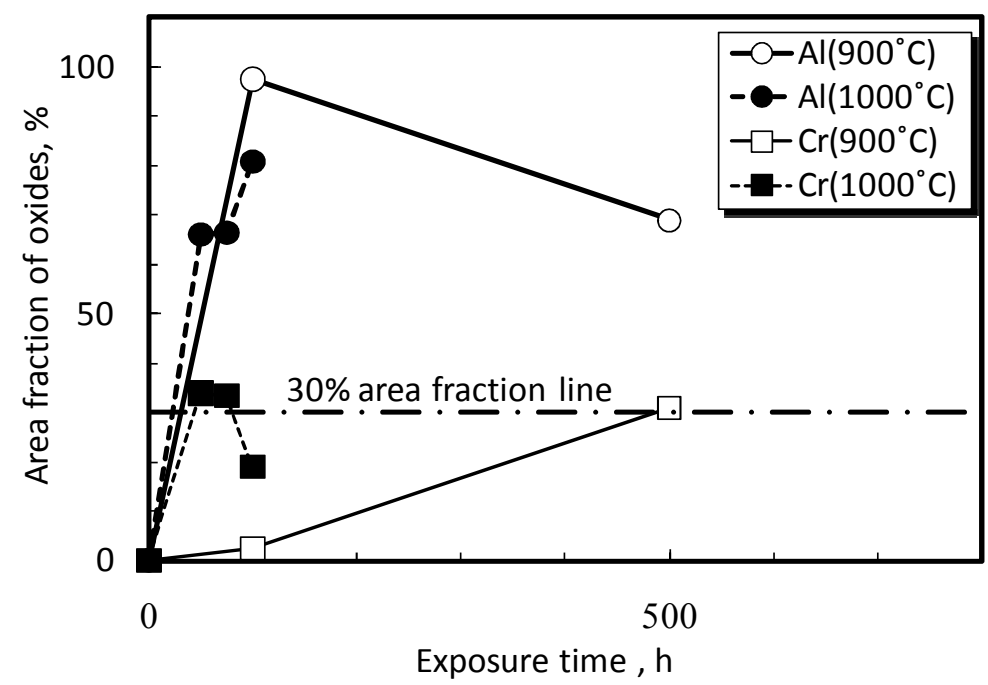

Fig.14 Relationship between the area fraction of oxides and exposure time.

\section{Conclusion}

Optical microscope, SEM and EBSD observation was conducted on TBC samples after thermal exposure. Obtained results are as follows.

1. EBSD observation was the quite effective tool for visualizing the splat crystallographic morphologies and revealing the cracking locations related to the microstructure of top coat in TBC.

2.Micro cracking of top coat could be divided into three typical patterns of intergranular type along large splats, of interfacial type between large splats and the cluster of small columnar splats and of transgranular type across the cluster of small columnar splats.

3. The cracking were supposed to occur during cooling process after crystallization because the crack paths were strongly affected by particle morphologies and across the small columnar particles. 
4.The transition from small distributed cracking to large macro cracking was closely related to the $\mathrm{Cr}$ oxide formation toward top coat.

Further investigation will be conducted to reveal the effect of crystallographic characteristics on micro cracking in TBCs by fully utilizing EBSD analysis techniques for more rational and precise damage evaluation of coating systems.

\section{References}

(1)Okazaki, M., The Potential for the Improvement of High Performance Thermal Barrier Coatings(Review), Material Science Research International, Vol.9, No.1(2003), pp.3-8.

(2)Annigeri, R., DiMascio, P.S., Orenstein, R.M., Zuiker, J.R., Thompson, A.M., Lorraine, P.W. and Dubois, M., Life Assessment of Thermal Barrier Coatings for Gas Turbine Applications, ASME 200-GT-580, (2000), pp.1-8.

(3)Wilkinson, A.J., Meaden, G. and Dingley, D.J., High Resolution Mapping of Strains and Rotations using Electron Backscatter Diffraction, Materials Science and Technology, Vol.22, No.11, (2006), pp.1271-1278. 